\title{
Pengaruh Doping Zirkonium (Zr) pada Konstanta Dielektrik dan Struktur Kristal $\mathrm{BaZr}_{x} \mathbf{T i}_{1-x} \mathbf{O}_{3}$
}

\author{
Fildzah Khairina Nisa, ${ }^{*}$ Anif Jamaluddin, dan Yofentina Iriani ${ }^{\dagger}$ \\ Program Studi Fisika Fakultas Keguruan dan Ilmu Pendidikan, Jurusan Fisika, FMIPA, \\ Universitas Sebelas Maret Surakarta, Jl. Ir. Sutami No. 36 A, Surakarta 57126
}

\begin{abstract}
Intisari
Barium zirkonium titanat $\left(\mathrm{BaZr}_{x} \mathrm{Ti}_{1-x} \mathrm{O}_{3}\right)$ dengan variasi mol dopan zirkonium (x) sebanyak 0,01 mol; 0,02 mol; dan 0,03 mol telah disintesis menggunakan metode reaksi fasa padat. Sampel disintering pada temperatur $1100^{\circ} \mathrm{C}$ dengan waktu tahan selama 2 jam. Sampel dikarakterisasi menggunakan instrumen XRD dan RLC meter untuk mengetahui pengaruh doping terhadap struktur kristal dan konstanta dielektrik $\mathrm{BaZr}_{x} \operatorname{Ti}_{1-x} \mathrm{O}_{3}$. Hasil analisis XRD menunjukkan bahwa $\mathrm{BaZr}_{x} \mathrm{Ti}_{1-x} \mathrm{O}_{3}$ memiliki struktur kristal tetragonal dengan $\mathrm{a}=\mathrm{b} \neq \mathrm{c}$. Ukuran kristal $\mathrm{BaZr}_{x} \mathrm{Ti}_{1-x} \mathrm{O}_{3}$ pada $\mathrm{x}=0,01 ; \mathrm{x}=0,02$; dan $\mathrm{x}=0,03$ masing-masing adalah $34 \mathrm{~nm}, 33 \mathrm{~nm}$, dan $38 \mathrm{~nm}$. Pengukuran RCL meter diperoleh konstanta dielektrik sebesar 331, 522, dan 641.
\end{abstract}

Abstract

Barium zirconium titanate $\left(\mathrm{BaZr}_{x} \mathrm{Ti}_{1-x} \mathrm{O}_{3}\right)$ with mole variations of zirconium $(\mathrm{x})$ dopant at $\mathrm{x}=0.01 ; \mathrm{x}=$ 0.02 ; and $\mathrm{x}=0.03$ has been fabricated by solid state reaction method. Sintering temperature was done at temperature $1100^{\circ} \mathrm{C}$ with holding time for $2 \mathrm{~h}$. Sample was characterized with XRD instrument and RLC meter to determine the effects of doping on the crystal structures and dielectric constant of $\mathrm{BaZr}_{x} \operatorname{Ti}_{1-x} \mathrm{O}_{3}$. The result of XRD analysis showed that $\mathrm{BaZr}_{x} \mathrm{Ti}_{1-x} \mathrm{O}_{3}$ has a tetragonal structure with $\mathrm{a}=\mathrm{b} \neq \mathrm{c}$. Crystalline size of $\mathrm{BaZr}_{x} \mathrm{Ti}_{1-x} \mathrm{O}_{3}$ at $\mathrm{x}=0.01 ; \mathrm{x}=0.02$; and $\mathrm{x}=0.03$ are $34 \mathrm{~nm}, 33 \mathrm{~nm}$, and $38 \mathrm{~nm}$. RLC meter measurement obtained the dielectric constant are 331,522 , and 641, respectively.

KATA KUNCI: barium zirconium titanate, doping, solid state reaction, dielectric constant

\section{PENDAHULUAN}

Ferroelektrik merupakan suatu material yang dapat mengalami polarisasi secara spontan ketika dikenai oleh suatu medan listrik dari luar. Polariasi terjadi ketika terdapat jarak antara muatan positif dan negatif pada material ferroelektrik sehingga terbentuk momen dipol atau pengutuban elektrik [1].

Material ferroelektrik memiliki sifat-sifat unik, yaitu sifat dielektrik, sifat piroelektrik, dan sifat piezoelektrik. Penemuan material ferroelektrik sebagai elemen aktif mulai dikembangkan dalam berbagai ukuran tergantung karakteristik dan kebutuhan yang diperlukan, seperti pengembangannya dalam dunia elektronika [1, 2].

Barium titanat $\left(\mathrm{BaTiO}_{3}\right)$ merupakan salah satu material ferroelektrik yang memiliki konstanta dielektrik tinggi dan tingkat kebocoran energi rendah sehingga banyak diaplikasikan dalam bidang elektronika seperti Dynamic Random Access Memories (DRAM), Ferroelectric Random Access Memories (FRAM), Controllers, sensor PCTR, detektor piroelektrik, perangkat pembangkit sinyal, dan kapasitor [24].

Barium titanat $\left(\mathrm{BaTiO}_{3}\right)$ memiliki stuktur atom $\mathrm{ABO}_{3}$ dengan A ditempati oleh atom $\mathrm{Ba}$ dan $\mathrm{B}$ ditempati atom Ti [2].

\footnotetext{
*E-MAIL: fildzahkhairinanisa@gmail.com

$\dagger^{\dagger}$ E-MAIL: yopen_2005@yahoo.com
}

Untuk meningkatkan sifat listrik, optik, dan sifat lainnya dari $\mathrm{BaTiO}_{3}$, maka dilakukan penelitian mengenai doping menggunakan atom $\mathrm{Ce}, \mathrm{La}, \mathrm{Hf}$, $\mathrm{Zr}$ yang dapat menggantikan posisi atom Ti pada $\mathrm{BaTiO}_{3}$ atau menggunakan atom $[5,6]$.

Doping terhadap $\mathrm{BaTiO}_{3}$ menggunakan atom $\mathrm{Zr}$ akan membentuk $\mathrm{BaZr}_{x} \mathrm{Ti}_{1-x} \mathrm{O}_{3}$ dengan $\mathrm{Zr}$ akan menggantikan posisi atom Ti pada struktur $\mathrm{BaTiO}_{3}$. Dikarenakan $\mathrm{Zr}$ memiliki jari-jari ion lebih besar, yaitu $0,086 \mathrm{~nm}$ dibandingkan Ti yang hanya $0,0745 \mathrm{~nm}$, maka dihasilkan struktur yang lebih stabil [5-8].

\section{METODE PENELITIAN}

Sintesis barium zirkonium titanat $\left(\mathrm{BaZr}_{x} \mathrm{Ti}_{1-x} \mathrm{O}_{3}\right)$ dilakukan dengan metode reaksi fasa padat. Massa $\mathrm{Zr}$ divariasi sebesar $\mathrm{x}=0,01, \mathrm{x}=0,02$, dan $\mathrm{x}=0,03$. Bahan-bahan pembentuk yaitu barium karbonat $\left(\mathrm{BaCO}_{3}\right)$, titanium dioksida $\left(\mathrm{TiO}_{2}\right)$, dan zirkonium dioksida $\left(\mathrm{ZrO}_{2}\right)$ dilakukan secara manual dengan proses penggerusan selama $6 \mathrm{jam}$. Penggerusan dilakukan agar terbentuk campuran yang homogen dengan ukuran partikel yang lebih kecil. $\mathrm{BaZr}_{x} \mathrm{Ti}_{1-x} \mathrm{O}_{3}$ powder kemudian dipress hingga membentuk bulk $\mathrm{BaZr}_{x} \mathrm{Ti}_{1-x} \mathrm{O}_{3}$ dengan menggunakan alat press hidrolik. Bulk $\mathrm{BaZr}_{x} \mathrm{Ti}_{1-x} \mathrm{O}_{3}$ disintering pada temperatur $1100^{\circ} \mathrm{C}$ dengan waktu tahan selama 2 jam.

Karakterisasi dilakukan menggunakan instrumen X-Ray Diffraction (XRD) Bruker D8 Advance bersumber radiasi Cu 


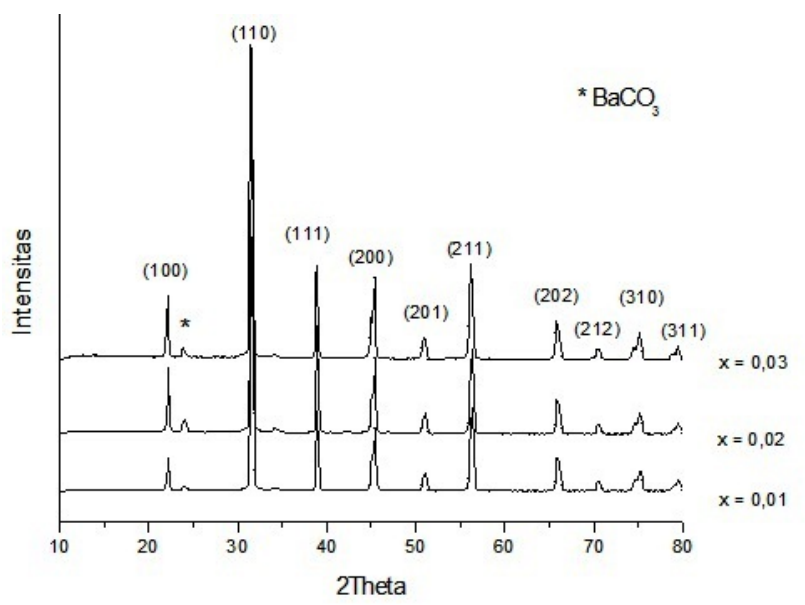

Gambar 1: Pola difraksi dari sampel $\mathrm{BaZr}_{x} \mathrm{Ti}_{1-x} \mathrm{O}_{3}$ dengan jumlah mol dopan $\mathrm{x}=0,01 ; \mathrm{x}=0,02 ;$ dan $\mathrm{x}=0,03$.

dengan panjang gelombang $1,5406 \stackrel{\AA}{A}$. Hasil uji XRD kemudian dicocokkan dengan database dari International Centre for Diffraction Data (ICDD). Data hasil uji XRD dapat digunakan untuk mengetahui struktur kristal, menghitung ukuran kristal dan kristalinitas dari sampel $\mathrm{BaZr}_{x} \mathrm{Ti}_{1-x} \mathrm{O}_{3}$.

Bulk $\mathrm{BaZr}_{x} \mathrm{Ti}_{1-x} \mathrm{O}_{3}$ diuji menggunakan instrumen RLC meter series Gwinstek untuk mengetahui nilai kapasitansi yang kemudian dapat digunakan untuk menghitung konstanta dielektrik sesuai dengan Pers. 1.

$$
K=\frac{C d}{\epsilon_{\circ} A}
$$

dengan, $\mathrm{K}$ merupakan konstanta dielektrik, $\mathrm{C}$ nilai kapasitansi, d ketebalan yang dimiliki bahan, dan A merupakan luasan dari bahan.

\section{HASIL DAN DISKUSI}

Karakterisasi dengan instrumen XRD dilakukan untuk mengidentifikasi tingkat kristalinitas dari sampel $\mathrm{BaZr}_{x} \mathrm{Ti}_{1-x} \mathrm{O}_{3}$. Hasil data XRD berupa grafik hubungan

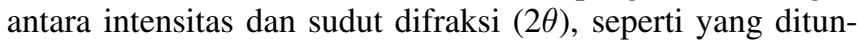
jukkan pada Gambar 1. Puncak-puncak difraksi yang muncul pada grafik XRD menunjukkan bahwa sampel $\mathrm{BaZr}_{x} \mathrm{Ti}_{1-x} \mathrm{O}_{3}$ dengan $\mathrm{x}=0,01, \mathrm{x}=0,02$, dan $\mathrm{x}=0,03$ merupakan material dengan struktur kristal. Puncak-puncak difraksi dari material $\mathrm{BaZr}_{x} \mathrm{Ti}_{1-x} \mathrm{O}_{3}$ kemudian dicocokkan dengan database International Centre for Diffraction Data (ICDD) dari barium titanat (PDF \#792265).

Hasil XRD menunjukkan bahwa intensitas tertinggi dari $\mathrm{BaZr}_{x} \mathrm{Ti}_{1-x} \mathrm{O}_{3}$ dengan $\mathrm{x}=0,01, \mathrm{x}=0,02$, dan $\mathrm{x}=0,03$ ditunjukkan pada sudut $31^{\circ}$ dengan bidang $\left(\begin{array}{lll}1 & 1 & 0\end{array}\right)$. Untuk mendapatkan puncak-puncak $\mathrm{BaZr}_{x} \mathrm{Ti}_{1-x} \mathrm{O}_{3}$ seperti yang diinginkan, dilakukan penghalusan (refinement) menggunakan metode Rietveld dengan software General Structure Analysis System (GSAS). Dari hasil analisis Rietveld, didapatkan nilai

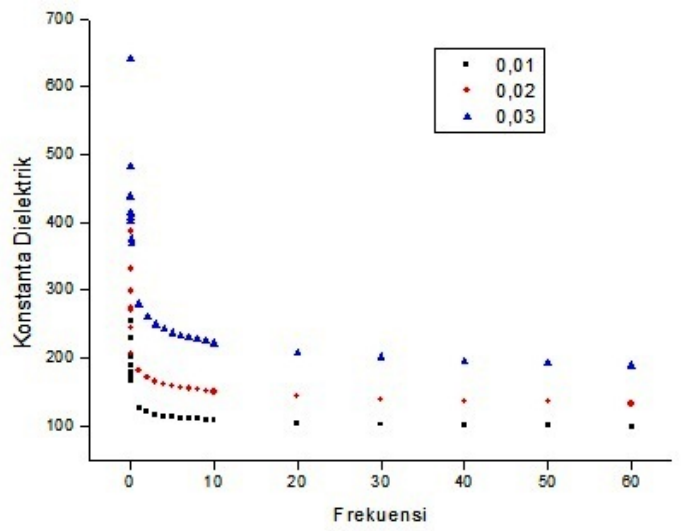

Gambar 2: Grafik hubungan konstanta dielektrik dengan variasi frekuensi.

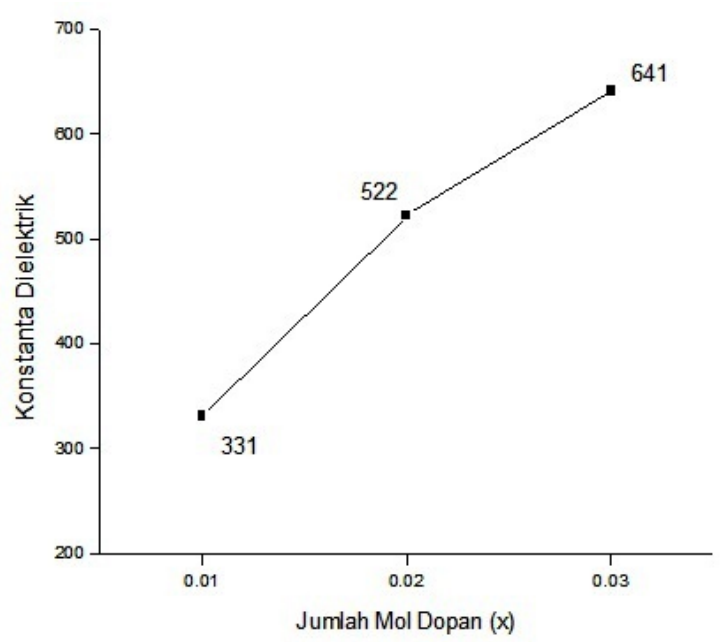

Gambar 3: Grafik hubungan konstanta dielektrik dengan variasi jumlah mol dopan.

parameter kisi yang dihasilkan dari refinement (penghalusan), seperti yang telah ditunjukkan pada Tabel I.

Hasil refinement GSAS menunjukkan bahwa parameter kisi akan semakin kecil ketika jumlah mol dopan $\mathrm{Zr}$ semakin besar. Hal ini dikarenakan atom $\mathrm{Zr}$ yang menggantikan posisi dari atom Ti memiliki jari-jari atom yang lebih besar sehingga nilai parameter kisi akan mengecil. Hasil refinement menunjukkan bahwa material $\mathrm{BaZr}_{x} \mathrm{Ti}_{1-x} \mathrm{O}_{3}$ memiliki struktur kristal tetragonal dengan nilai parameter kisi $\mathrm{a}=\mathrm{b} \neq$ c.

Berdasarkan hasil perhitungan ukuran kristal sampel $\mathrm{BaZr}_{x} \mathrm{Ti}_{1-x} \mathrm{O}_{3}$ dengan variasi mol dopan terlihat bahwa semakin banyak jumlah mol dopan $\mathrm{Zr}$ yang diberikan pada $\mathrm{BaTiO}_{3}$ maka ukuran kristalnya semakin besar, seperti yang ditunjukkan pada Tabel II.

Hasil karakterisasi menggunakan instrumen RLC meter berupa nilai kapasitansi bahan dan faktor disipasi. Pengukuran dengan RLC meter ini menggunakan frekuensi mi- 
TABEL I: Parameter kisi $\mathrm{BaZr}_{x} \mathrm{Ti}_{1-x} \mathrm{O}_{3}$ dengan $\mathrm{x}=0,01, \mathrm{x}=0,02$, dan $\mathrm{x}=0,03$.

\begin{tabular}{cccc}
\hline \hline Jumlah Mol & \multicolumn{3}{c}{ Parameter Kisi } \\
dopan & $\mathrm{a}=\mathrm{b}(\AA)$ & $\mathrm{c}(\AA)$ & $\mathrm{c} / \mathrm{a}$ \\
\hline 0,01 & 4,0001 & 4,0033 & 1,0008 \\
0,02 & 3,9989 & 4,0299 & 1,0075 \\
0,03 & 3,9995 & 4,0301 & 1,0077 \\
\hline \hline
\end{tabular}

TABEL II: Ukuran kristal dan kristalinitas $\mathrm{BaZr}_{x} \mathrm{Ti}_{1-x} \mathrm{O}_{3}$ dengan $\mathrm{x}=0,01, \mathrm{x}=0,02$, dan $\mathrm{x}=0,03$.

\begin{tabular}{ccc}
\hline $\begin{array}{c}\text { Jumlah Mol } \\
\text { dopan }\end{array}$ & $\begin{array}{c}\text { Ukuran } \\
\text { kristal }(\mathrm{nm})\end{array}$ & $\begin{array}{c}\text { Kristalinitas } \\
(\%)\end{array}$ \\
\hline 0,01 & 34 & 96,01 \\
0,02 & 33 & 95,48 \\
0,03 & 38 & 97,00 \\
\hline \hline
\end{tabular}

nimun $0,01 \mathrm{kHz}$ hingga frekuensi $60 \mathrm{kHz}$. Hasil pengukuran RLC meter ini seperti yang ditunjukkan pada Gambar 2. Nilai kapasitansi akan semakin besar ketika frekuensi yang diberikan semakin kecil. Dikarenakan hubungan kapasitansi dengan konstanta dielektrik berbanding lurus seperti yang ditunjukkan oleh Pers.(1), maka konstanta dielektrik yang diperoleh juga semakin besar ketika frekuensi yang diberikan semakin kecil.

Hasil perhitungan konstanta dielektrik, seperti yang ditunjukkan pada Gambar 3 menunjukkan bahwa konstanta dielektrik yang dihasilkan oleh $\mathrm{BaZr}_{x} \mathrm{Ti}_{1-x} \mathrm{O}_{3}$ akan semakin besar ketika jumlah mol dopan $\mathrm{Zr}$ semakin bertambah. Konstanta dielektrik yang dihasilkan pada pengukuran frekuensi 0,01 $\mathrm{kHz}$ adalah sebesar 331, 522, dan 641 untuk $\mathrm{x}=0,01 ; \mathrm{x}=$ 0,$02 ;$ dan $\mathrm{x}=0,03$.

\section{SIMPULAN}

Barium zirkonium titanat $\left(\mathrm{BaZr}_{x} \mathrm{Ti}_{1-x} \mathrm{O}_{3}\right)$ telah berhasil dibuat dengan melakukan doping terhadap $\mathrm{BaTiO}_{3}$ menggunakan atom zirkonium ( $\mathrm{Zr}$ ) dengan metode reaksi fasa padat. Variasi jumlah mol dopan $\mathrm{Zr}$ yang diberikan mempengaruhi struktur kristal dan konstanta dielektrik dari $\mathrm{BaZr}_{x} \mathrm{Ti}_{1-x} \mathrm{O}_{3}$. Dengan bertambahnya jumlah mol Zr, maka ukuran kristal yang dihasilkan semakin besar. Parameter kisi yang dihasilkan juga akan semakin besar ketika jumlah mol dopan semakin besar dengan $\mathrm{a}=\mathrm{b} \neq \mathrm{c}$. Konstanta dielektrik yang dihasilkan oleh $\mathrm{BaZr}_{x} \mathrm{Ti}_{1-x} \mathrm{O}_{3}$ pada pengukuran menggunakan frekuensi $0,01 \mathrm{kHz}$ akan bertambah besar ketika jumlah mol Zr semakin besar, yaitu sebesar 331, 522 dan 641 untuk $\mathrm{x}=$ 0,$01 ; x=0,02 ;$ dan $x=0,03$.

\section{Ucapan Terima Kasih}

Penulis mengucapkan terima kasih kepada DIKTI yang telah mendanai penelitian ini melalui Program Kreativitas Mahasiswa (PKM).
[1] N. Nurhadi, A. Jamaluddin, Y. Iriani, Jurnal Teori dan Aplikasi Fisika, 1(2), 191-198 (2013).

[2] M. Istiqomah, A. Jamaluddin, Y. Iriani, Jurnal Fisika Indonesia, XVIII(53), ISSN: 1410-2994 (2014).

[3] A. Zaidah, Suwarni, Y. Iriani, Pengaruh Suhu Sintering Pada Barium Stronsium Titanat $\left(\mathrm{Ba}_{0,2} \mathrm{Sr}_{0,8} \mathrm{TiO}_{3}\right)$ Terhadap Konstanta Dielektrik yang Dibuat dengan Metode Solid State Reaction, Prosiding Pertemuan Ilmiah XXIX HFI Jateng dan DIY, ISSN : 0853-0823, 2015.
[4] Z. Sun, et al., Ceramics International, 40, 3589-3594 (2014)

[5] O.A.A. Abdelal, American Journal of Materials Science, 3(6), 179-188 (2013).

[6] X. Liu, et al., Integrated Ferroelectrics, 150, 66-74 (2014), ISSN: 1058-4587.

[7] S.K. Dash, et al., Indian Journal Physics, 88(2), 129-135 (2014).

[8] F. Moura, et al., Journal of Alloys and Compound, 462, 129-134 (2008). 